\title{
FISIOPATOGENIA DA HIPERTENSÃO ARTERIAL
}

\author{
PATHOPHYSIOLOGY OF PRIMARY HYPERTENSION
}

Eduardo M. Krieger, Kleber G. Franchini, José Eduardo Krieger

Unidade de Hipertensão - Instituto do Coração da Faculdade de Medicina da Universidade de São Paulo

CoRRESPONDÊNCIA: Eduardo M. Krieger; Coordenador da Unidade de Hipertensão do INCOR - Instituto do Coração da Faculdade de Medicina da Universidade de São Paulo - Av. Enéas Carvalho de Aguiar, 44 - CEP: 05403-000 - São Paulo - SP

KRIEGER EM; FRANCHINI KG \& KRIEGER JE. Fisiopatogenia da hipertensão arterial. Medicina, Ribeirão Preto, 29: 181-192, abr./set. 1996.

RESUMO: Na hipertensão primária, ou essencial, a elevação da resistência periférica é a principal responsável pelo aumento da pressão arterial. Isso ocorre pela redução do calibre das arteríolas determinada pela combinação, em grau variado, de fatores funcionais e fatores estruturais. A vasoconstrição pode ser causada pela produção excessiva de fatores pressores (angiotensina, vasopressina, endotelina e sistema nervoso simpático etc), ou pela deficiência dos fatores depressores (óxido nítrico, prostaciclina e peptídio natriurético atrial). O componente estrutural é, geralmente, representado pela hipertrofia da camada média que passa a ocupar parte do espaço intravascular. Importante ressaltar que os fatores que, ativamente, contraem ou dilatam os vasos têm, também, efeitos tróficos sobre a camada muscular, estimulando ou inibindo o seu espessamento. A redução da luz das arteríolas pode resultar, igualmente, de "remodelagem", quando ocorre redução tanto do diâmetro interno como externo, sem modificações da massa. O componente genético é responsável pela produção dos complexos fatores pressores e depressores que regulam a pressão arterial. Também, ele é o responsável pela susceptibilidade individual aos fatores ambientais (sal e estresse, por exemplo), que sobrecarregam o sistema e podem gerar o desequilíbrio causador da hipertensão.

UNITERMOS: Hipertensão. Resistência Vascular. Vasoconstrição. Vasodilatação. Hipertrofia. Genética.

\section{INTRODUÇÃO}

Para que a troca de materiais ao nível dos capilares entre o sangue e as células do organismo se faça de forma eficiente, é essencial, particularmente, em tecidos com o metabolismo muito sensível, como no sistema nervoso central, que o aporte de oxigênio pelo sangue arterial seja constante e não intermitente. Mas como conseguir um fluxo constante nos capilares se a bomba cardíaca lança o sangue nas artérias, somente durante $1 / 3$ do tempo, e gasta a maior parte do período no processo de enchimento, recebendo o sangue das veias?
Isso é possível graças à existência das arteríolas que estão antes dos capilares e que pelo seu pequeno número e reduzido calibre, opõem à circulação do sangue uma elevada resistência. É essa resistência que faz com que o ventrículo ao esvaziar o seu conteúdo nas artérias encontre maior facilidade em distendê-las do que em drenar, instantaneamente, todo o sangue pelas arteríolas. $\mathrm{O}$ volume de sangue armazenado durante o esvaziamento (sístole) será enviado à periferia no período em que o ventrículo estiver no processo de enchimento (diástole). Portanto, o sistema arterial funciona como uma câmara elástica de alta pressão que amortece as flutuações de descarga da 
bomba cardíaca, assegurando um fluxo permanente ao nível dos capilares. Durante a sístole ventricular, a pressão se eleva até atingir um máximo, chamada, também, de pressão sistólica. Depois, à medida que o sangue acumulado vai sendo transferido para os capilares, a pressão nas artérias vai caindo, lentamente, até atingir um valor mínimo (pressão diastólica), imediatamente antes de iniciar-se o ciclo seguinte. Graças à combinação entre a descarga intermitente da bomba cardíaca e à alta resistência das arteríolas, acoplada à elasticidade das artérias, o organismo consegue manter um aporte constante de sangue para irrigar os tecidos. O custo desse processo é que as artérias são, permanentemente, submetidas a uma elevada pressão pulsátil: cerca de 120 milímetros de mercúrio de pressão máxima, ou sistólica, e cerca de 80 milímetros de mercúrio de pressão mínima ou diastólica.

Se a resistência das arteríolas, que já é elevada, aumentar mais ainda, deve haver uma elevação adicional de pressão no sistema arterial para assegurar um fluxo inalterado nos capilares. Elevando-se a pressão mínima no sistema (acima de 90 milímetros de mercúrio), o coração é obrigado a aumentar também a pressão de descarga (a máxima tende a ficar acima de 130-140 milímetros de mercúrio). Como a resistência das arteríolas depende basicamente do seu calibre, sua redução eleva a pressão arterial, sendo geralmente responsável pela hipertensão. Adiminuição do calibre acontece pelo aumento da contração da musculatura que regula a luz do vaso, pelo espessamento dessa musculatura que passa a ocupar parte da luz, ou pela combinação dos dois fatores. A hipertensão, portanto, pode ser causada pelo desiquilíbrio entre a produção aumentada de fatores vasoconstritores (os nervos simpáticos e as catecolaminas, a angiotensina, a endotelina etc) e/ou pela produção deficiente de fatores vasodilatadores (óxido nítrico, bradicinina, etc.), com o conseqüente aumento do grau de contração da musculatura das arteríolas. Mas fatores anatômicos, estruturais, também podem reduzir o calibre vascular de forma permanente. Até mesmo os fatores vasoconstritores, que ativamente contraem o vaso, exercem um efeito trófico, estimulando o espessamento da camada muscular (hipertrofia muscular).

Esquematicamente, a resistência elevada, que acarreta hipertensão em um determinado indivíduo, pode resultar do aumento da produção de fatores vasoconstritores e/ou da diminuição de fatores vasodilatadores, ou, ainda, da maior capacidade de reação da musculatura das arteríolas aos estímulos normais. A combinação desses fatores poderia determinar uma diminuição ativa, funcional, do calibre das arteríolas e a conseqüente hipertensão. No entanto, resultado semelhante pode ser produzido por uma alteração anatômica ou estrutural do vaso, o espessamento da parede vascular que, como já foi mencionado, passa a ocupar parte do espaço intravascular, antes livre. Isso, também, vai depender de características individuais que alteram o equilíbrio dos fatores que estimulam e os que inibem o crescimento da musculatura vascular. Mais recentemente, especialmente pelos trabalhos do grupo de Mulvany (Figura 1), admite-se que a redução da luz das artérias possa ocorrer não só pela hipertrofia da parede, mas também, por uma "remodelagem" quando há redução de todos os diâmetros, externo e inter-

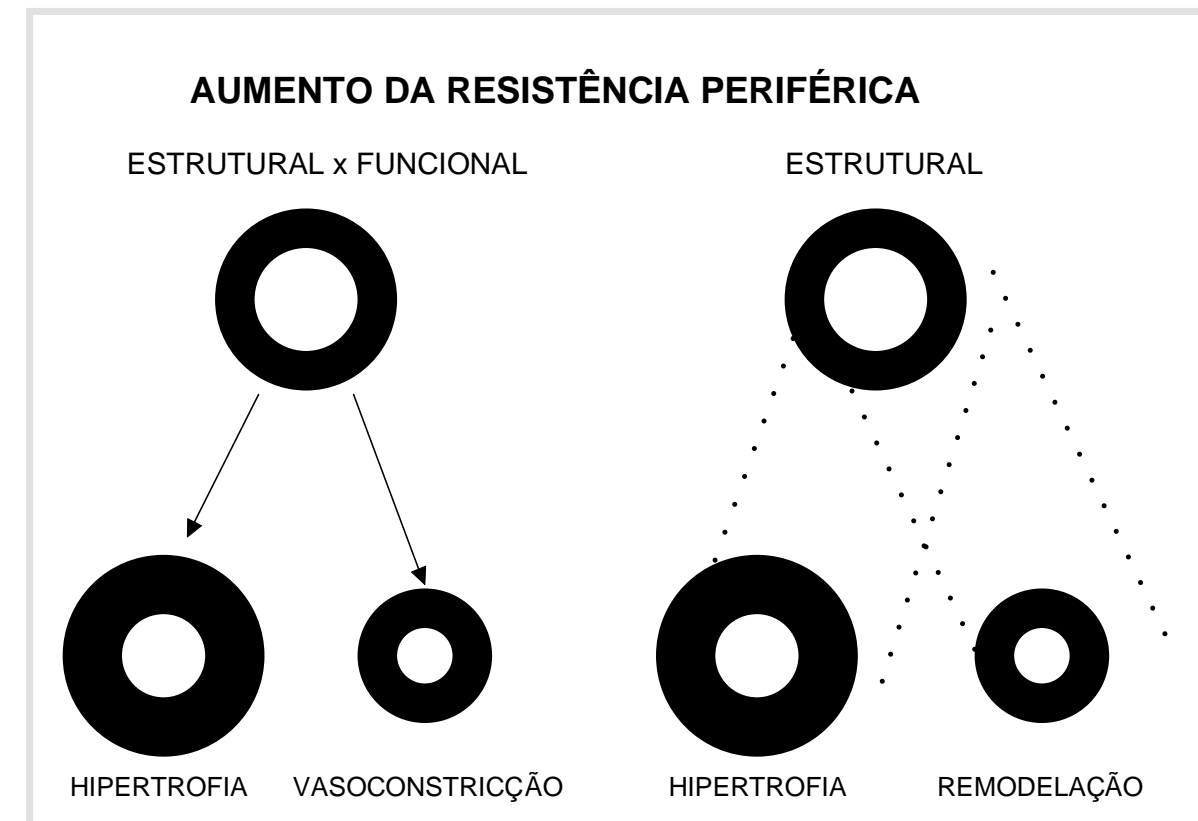

Figura 1: A redução do calibre das arteríolas pode ocorrer por processo ativo (funcional) de vasoconstrição ou por hipertrofia da camada média muscular (estrutural). Mais recentemente, vem sendo demonstrado que o componente estrutural pode ser determinado não só por espessamento da parede, como também por "remodelação", quando há redução global dos diâmetros externo e interno, sem modificação da massa. 
no, sem modificações da massa. É de se esperar que a diminuição do calibre dependa, em cada indivíduo, da combinação em graus variados de fatores estruturais e fatores funcionais, ativos. Admite-se que uma arteríola com a musculatura espessada reaja mais, isto é, "amplifique" os estímulos vasoconstritores, mesmo aqueles considerados fisiológicos, como os promovidos pelo sistema nervoso simpático.

Em síntese, pode-se dizer que cada indivíduo traz uma carga genética que é responsável pela produção dos complexos fatores que regulam a sua pressão arterial de momento-a-momento e no decorrer da vida. Mas não só a carga genética é responsável pelo equilíbrio dos fatores que mantêm a pressão arterial, dentro das cifras normais. Solicitações ambientais (sal e álcool em excesso, fumo e excitação psicoemocional, por exemplo) poderão sobrecarregar os sistemas e deflagrar o desiquilíbrio causador da hipertensão.

Embora o débito cardíaco aumentado possa colaborar para a produção da hipertensão, especialmente na hipertensão lábil dos jovens, na maioria dos casos com hipertensão permanente "fixa", é a elevação da resistência periférica a responsável pela hipertensão. Portanto, na presente revisão, os mecanismos que alteram o calibre das arteríolas serão analisados (Figura 2).

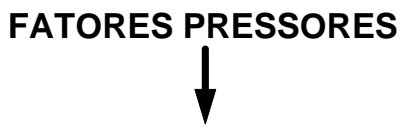

\section{HIPERTENSÃO}

FATORES DEPRESSORES $\downarrow$

NORMOTENSÃO

1. Fatores Endoteliais (NO)

2. Cininas - Prostaciclina

3. Peptideo Natriurético Atrial

\section{Simpático \\ 2. Sistema Renina/Angiotensina \\ 3. Vasopressina \\ 4. Endotelina}

Figura 2: A pressão arterial é, continuamente, influenciada por complexos sistemas pressores e depressores. A hipertensão é provocada pela ruptura no equilíbrio entre os dois fatores.

\section{VASOS DE RESISTÊNCIA}

A resistência ao fluxo de sangue no sistema arterial é importante a partir das pequenas artérias alimentadoras externas ao parênquima dos órgãos (diâmetro de 100 a $500 \mu \mathrm{m}$ ) e se estende para a árvore arteriolar (diâmetro de 10 a $100 \mu \mathrm{m}$ ) no seu interior. As artérias alimentadoras e as arteríolas proximais (diâmetro de 60 a $100 \mu \mathrm{m}$ ) controlam a magnitude do fluxo sanguíneo para o órgão, enquanto as arteríolas intermediárias (diâmetro de 15 a $60 \mu \mathrm{m}$ ) controlam a distribuição de fluxo, no interior do tecido, e as arteríolas terminais controlam a perfusão capilar, i.e., a superficie para trocas entre as células parenquimatosas e o sistema cardiovascular.

A parede dos vasos de resistência consiste, primariamente, de células musculares lisas, separadas da luz por uma camada de células endoteliais. Subs- tâncias vasoativas são produzidas pelas células endoteliais, células musculares lisas, células parenquimatosas e, também, são liberadas pelas terminações nervosas na intimidade das camadas de células musculares lisas. Além disso, os vasos são, continuamente, expostos a substâncias vasoativas circulantes (angiotensina, vasopressina, por exemplo) que podem atuar como agentes vasoativos, tanto por ação direta no musculo liso vascular como por intermediários liberados das células da estrutura vascular. Os vasos são, também continuamente, expostos a forças como pressão transmural e atrito do fluxo sanguíneo na camada endotelial. Esses múltiplos estímulos interagem para controlar a atividade contrátil das células musculares lisas vasculares e, portanto, controlar o diâmetro do vaso, controlando a resistência periférica e o fluxo sanguíneo. 


\section{RESPOSTA MIOGÊNICA E INFLUÊNCIA DO FLUXO}

Resposta miogênica. A resposta miogênica refere-se à propriedade dos vasos de responderem com vasoconstrição ou vasodilatação a variações na pressão transmural. As respostas miogênicas ocorrem, independentemente, das células endoteliais ou células parenquimatosas. Aumento no estiramento (tensão radial) na parede dos vasos é percebido pelas células musculares lisas, resultando em ativação de vários mensageiros intracelulares que aumentam a concentração de cálcio intracelular. Por outro lado, diminuição no estiramento das células musculares lisas leva a relaxamento do vaso por diminuir a quantidade de cálcio intracelular disponível para o aparelho contrátil da célula. Os vasos de resistência apresentam máxima reatividade miogênica em pressões fisiológicas, a resposta relativa aumentando com a diminuição do tamanho do vaso.

A resposta miogênica está aumentada na hipertensão arterial, o que contribui para a redução no diâmetro e aumento na espessura da parede, observada em arteríolas de indivíduos ou animais de experimentação hipertensos. Os mecanismos responsáveis por essa elevação na reatividade miogênica em estados hipertensivos não estão esclarecidos. Liberação de substâncias vasoativas (derivados do acido aracdônico, por exemplo) ou ativação de mecanismos de membrana levando à ativação direta de mecanismos intracelulares, responsáveis pela liberação de cálcio intracelular e que foram apontados como responsáveis pela resposta miogênica em alguns estudos experimentais. Estes mecanismos podem estar alterados na hipertensão, justificando a hiperreatividade. Por outro lado, o aumento da massa muscular das arteríolas, por si só, pode contribuir importantemente para o aumento na reatividade miogênica na hipertensão arterial, amplificando as respostas.

Influência do fluxo. Evidências de que o fluxo sanguíneo pode regular o tono vascular remontam ao início do século, no entanto, somente em anos recentes o papel do endotélio, como mediador desse fenômeno, foi definido. A vasodilatação endotélio-dependente foi confirmada em artérias de grande calibre e em vasos de resistência. Existem evidências experimentais de que o aumento de fluxo envolve a liberação de fatores endoteliais relaxadores cujo principal representante é o óxido nítrico e nitroderivados relacionados e que a diminuição de fluxo aumenta a liberação de endotelina.
A pressão intra-arterial (tensão radial no vaso) exerce pouco ou nenhum efeito sobre o endotélio no controle do tono vascular, seu principal efeito ocorre, sobre a resposta contrátil das célula musculares lisas (ver resposta miogênica). A principal força hemodinâmica reguladora do endotélio é o atrito exercido pelo fluxo de sangue na superfície luminal do vaso. Estimase que esse atrito seja de 20 a 40 dinas $/ \mathrm{cm}^{2}$ em vasos de grande calibre. Apesar de as evidências experimentais indicarem o atrito como a força hemodinâmica responsável pela liberação de fatores relaxadores dos vasos, os mecanismos pelos quais essas forças são detectadas e convertidas em sequiências de respostas biológicas são ainda pouco conhecidos. $\mathrm{O}$ atrito estimula a célula endotelial, atuando na sua superfície. Além disso, o atrito produz deformações nas células endoteliais na direção do fluxo, desencadeando aumento de tensão na estrutura celular, em decorrência da presença de filamentos de actina, miosina e tropomiosina que compõem o citoesqueleto. Proteínas de membrana ativadas, diretamente, pelo atrito ou pelo aumento da tensão, em decorrência da deformação do citoesqueleto, são candidatas a serem os mecanotransdutores que geram os sinais intracelulares. O protótipo de sensor mecânico na superfície pode ser uma molécula ou complexo molecular cuja função esteja relacionada ao estado de tensão. O papel de mecanotransdutor poderia ser exercido tanto por canais ionicos, como por outras proteínas ligadas à membrana celular, como receptores de membrana ligados a proteínas G, por exemplo. A identidade e a maneira pela qual esses transdutores levam à seqüência de eventos intracelulares permanece desconhecida. No entanto, pelo menos três substâncias diferentes foram demonstradas quando tiveram a liberação e produção por células endoteliais, controlada pelo atrito, a) óxido nítrico; b) prostaciclina e c) endotelina. Essas substâncias exercem seus efeitos sobre células musculares lisas adjacentes ao local de sua liberação.

\section{FATORES PRESSORES}

\subsection{Sistema Nervoso Autonômico}

Vasodilatação e vasoconstrição dos vasos de resistência são fundamentais para os ajustes a aumentos e diminuições da demanda metabólica dos tecidos. Durante os ajustes de fluxo regional, que ocorrem em situações fisiológicas como exercício, mergulho, hemorragia, etc., o simpático domina e coordena o grau 
de vasoconstrição nas diversas regiões da circulação sistêmica. Essa resposta neural capacita a rápida redistribuição do fluxo sanguíneo às áreas funcionalmente importantes para atividades específicas. Essa redistribuição do fluxo sanguíneo é coordenada por uma combinação de atividade simpática gerada centralmente, e por sua modulação por receptores, localizados em posições estratégicas do aparelho cardiovascular (sensores de tensão na parede dos grandes vasos e coração), principalmente os pressorreceptores arteriais. Além disso, a atividade tônica basal do simpático (também, modulada ciclo cardíaco-ciclo cardíaco pelos pressorreceptores) contribui de maneira importante para o tono basal dos vasos de resistência. A importância da contribuição do sistema nervoso simpático para o tono vascular normal é aparente pela queda, em torno de $30 \mathrm{mmHg}$, na pressão arterial média seguindo-se ao bloqueio farmacológico $\alpha$-adrenérgico.

Os vasos de resistência são ricamente inervados pelo simpático. Os axônios dos neurônios simpáticos pós-ganglionares ramificam-se em pequenos ramos formando um plexo primário, localizado na adventícia. Os feixes dão origem a fibras que formam um plexo localizado nas proximidades das células musculares lisas e exibem varicosidades onde as fibras são, parcial ou inteiramente, destituídas da camada de mielina. São nesses pontos que as fibras se aproximam da superfície da célula muscular lisa e estabelecem o contato neuromuscular. Comparadas às sinapses centrais, cujas fendas sinápticas não ultrapassam $20 \mathrm{~nm}$, as unidades neuroefetoras do simpático vascular apresentam fendas de cerca de $100 \mathrm{~nm}$. A concentração de norepinefrina nas arteríolas é da ordem de 10-100 $\mu \mathrm{g} / \mathrm{g}$ de tecido seco e seu "turnover" em torno de 3 horas. As varicosidades contém de 500 a 1500 vesículas sinápticas e a concentração de norepinefrina, em cada sinapse, é estimada em torno de $2.4 \mathrm{M}$.

A concentração de norepinefrina no espaço extracelular é difícil de ser estimada, em condição basal e durante ativação neural. Somente uma pequena fração das células musculares lisas é diretamente inervada por nervos simpáticos, o que indica que as células musculares lisas são, elétrica e mecanicamente, acopladas, transmitindo o sinal da ativação simpática entre si. A norepinefrina liberada na fenda liga-se a sítios lipoprotéicos (receptores) na membrana das célula musculares lisas, onde a resposta vasoconstritora é deflagrada. A norepinefrina é removida da fenda por reabsorção ativa pela terminação neural e por difusão para os capilares. Aproximadamente, $80 \%$ da norepinefrina liberada é reincorporada ao terminal e reestocada. A quantidade que se difunde para os capilares é distribuída por todo o organismo e serve como um índice grosseiro da atividade do sistema nervoso simpático. Nos vasos, a norepinefrina liga-se, prevalentemente, a receptores $\alpha$-adrenérgicos causando aumento na permeabiliade ao cálcio tanto na membrana celular como no retículo sarcoplasmático. O aumento da quantidade de cálcio intracelular inicia a contração da célula muscular lisa. Em algumas regiões, existem nas células musculares lisas receptores $\beta$ adrenérgicos que, quando ativados, causam vasodilatação. Quando a norepinefrina é infundida em tecidos que contenham ambos, $\alpha$ e $\beta$ receptores (músculo esquelético), o efeito nos receptores $\alpha$ predomina e as arteríolas se contraem. Somente quando os receptores $\alpha$ são bloqueados, o efeito dos receptores $\beta$ predomina e a dilatação arteriolar é observada. É interessante que, quando a norepinefrina é liberada da terminação nervosa, observa-se pouco ou nenhum efeito $\beta$-adrenérgico, mesmo quando os receptores $\alpha$ estão bloqueados. Portanto, a norepinefrina liberada das terminações nervosas age, predominantemente, nos receptores $\alpha$ causando vasoconstrição.

Há variações regionais significativas na responsividade das arteríolas à ativação simpática. Um grande número de fatores capacitam o sistema nervoso a influenciar o tono vascular diferencialmente nos diversos órgãos: 1) um fator importante refere-se à densidade de inervação das arteriolas, nos diversos órgãos. A inervação das arteríolas é especialmente densa em vasos da pele, órgãos esplâncnicos, músculo esquelético, rins e tecido adiposo; 2) a sensibilidade do músculo liso vascular à norepinefrina varia de região para região, o que é, em parte, dependente da densidade de receptores $\alpha$-adrenégicos nos vasos; 3) há uma heterogeneidade de receptores $\alpha$-adrenérgicos entre órgãos; 4) a reabsorção de norepinefrina pela terminação nervosa difere de região para região; 5) a estrutura e tamanho dos vasos varia de tecido para tecido e contribui para a heterogeneidade das respostas à ativação simpática.

Variações regionais da responsividade das arteríolas à atividade do simpático, também, resultam de variações nos níveis regionais do tono miogênico basal. O nível de tono miogênico é variável de região para região, sendo maior no coração, cérebro e músculo esquelético e menor nos rins. A vasoconstrição produzida pela ativação simpática eleva a resistência acima do tono basal por vasoconstrição ativa, 
mas somente pode diminuir a resistência, abaixo do tono basal, por dilatação também ativa. Assim, em regiões com elevada vasoconstrição simpática tônica uma vasodilatação considerável pode ser alcançada pela retirada do tono simpático basal. Em contraste, em regiões com baixo tono simpático, vasodilatação mínima pode ser alcançada com a retirada do tono simpático.

É importante reconhecer que o fluxo sanguíneo e a resistência periférica estão, intimamente, ligados à taxa metabólica em vários territórios. Um aumento na atividade metabólica nesses leitos, normalmente, resulta em vasodilatação, que suplanta a ação vasoconstritora do simpático. Finalmente, agentes humorais circulantes podem tanto impedir como potenciar a resposta vasoconstritora neurogênica. Por exemplo, a angiotensina II potencia os efeitos da norepinefrina, enquanto substâncias vasodilatadoras tais como, ANP atenuam a resposta vasoconstritora neurogênica. Dessa forma, a influência da atividade simpática na circulação regional pode, também, variar dependendo dos níveis circulantes, assim como de diferenças regionais na reatividade vascular a hormônios vasoativos.

A contribuição do simpático para a patogênese da hipertensão arterial é, ainda, controvertida. Modelos experimentais utilizando manipulações de aferentes neurais, bem como de núcleos do sistema nervoso central, que exercem inibição tônica sobre o simpático apresentam elevações discretas da pressão arterial, não sustentáveis quando o tono simpático se normaliza. Também diferentes modalidades de estresses, somente, elevam a pressão arterial enquanto durar o estímulo. Isso indica que alterações isoladas do simpático, em animais sem outro fator predisponente à hipertensão arterial, não são capazes de produzir alterações estruturais permanentes, suficientes para a manutenção do estado de resistência periférica elevada, característica da hipertensão estabelecida.

Há evidências de que indivíduos com hipertensão "borderline"ou leve apresentam hipertonia simpática demonstráveis em estudos farmacológicos, com bloqueio seletivo de receptores adrenérgicos cardíacos e vasculares, pela presença de níveis plasmáticos de catecolaminas e, mais recentemente, por aumento na atividade do nervo simpático peroneiro. Durante o curso da hipertensão o tono simpático se normaliza. No entanto, o simpático continua sendo um fator importante para a manutenção de níveis elevados de resistência periférica e pressão arterial. Em hipertensões estabelecidas, os vasos de resistência apresen- tam-se com hipertrofia da camada média. As respostas de vasos hipertrofiados tornam-se amplificadas a agentes vasoconstritores, e menor descarga neural simpática é necessária para manter o mesmo grau de vasoconstrição. Outra indicação de que o simpático pode estar envolvido na manutenção de níveis elevados de pressão arterial, em pacientes hipertensos, é fornecida pela análise da variabilidade da pressão arterial, nas 24 horas. Pacientes hipertensos apresentam aumento significativo na variabilidade da pressão arterial. Aumentos na amplitude das variações de pressão arterial durante situações comportamentais específicas, dependente basicamente do componente neurogênico, estariam envolvidos no aumento da variabilidade verificado em pacientes hipertensos, além de contribuir para os níveis de pressão arterial elevados, nas 24 horas.

\subsection{Sistema renina-angiotensina}

O sistema renina-angiotensina, tradicionalmente, é conhecido como um sitema endócrino cuja substância ativa, a Angiotensina II (Ang II), é formada por uma clivagem seqüencial do angiotensinogênio pela renina e a enzima conversora. A Ang II, agindo de forma multivariada, participa da manutenção da homeostasia cardiovascular, através do controle fino do metabolismo de fluídos e eletrólitos. Recentemente, com a utilização das ferramentas da biologia molecular demonstrou-se, inequivocamente, através da identificação de RNAs mensageiros que os componentes do SRA não se limitam àqueles órgãos tradicionais, criando-se a possibilidade da existência de SRAs teciduais funcionalmente distintos. A importância relativa destes sistemas compartimentalizados em situações fisiológicas e fisiopatológicas é objeto de intensa investigação em diversos laboratórios.

Apesar de a AngII ser responsável pela grande maioria das respostas normalmente atribuídas ao SRA, vários metabólitos do octapeptídeo como o AngIII, a A1-7 e a AngIV têm sido associados a respostas específicas. A Ang II influencia o tonus vascular, a liberação de aldosterona, a reabsorção de sódio no túbulo renal proximal, o mecanismo de sede e liberação de vasopressina, e mais recentemente outras funções, também, estão sendo atribuídas ao peptídio, devidas a sua propriedade de influenciar a expressão de outros genes. A Ang II parece exercer efeito nos genes do SRA. Acredita-se que a Ang II participe da alça de retro-alimentação negativa sobre a produção da ECA e, ainda, sobre outros genes que estão envolvidos em alterações 
fenotípicas estruturais e funcionais de várias células. A modificação destes genes está relacionda às alterações estruturais e funcionais, observadas em doenças cardiovasculares. Por isso a Ang II, hoje, é considerada "fator de crescimento". Neste novo paradigma, as substâncias vasoconstritoras como a Ang II, a endotelina e as catecolaminas seriam substâncias pró-crescimento, enquanto que os vasodilatadores como o $\mathrm{NO}$, o ANP e a prostaglandina PGI2 teriam ação anticrescimento. Neste contexto, a hipertensão arterial é considerada um distúrbio dos sistemas de controle onde há predominância de substâncias vasoconstritoras, pró-crescimento, sobre as vasodilatadores, anticrescimento.

A Ang II exerce a maior parte de suas funções conhecidas através da interação com o receptor do tipo AT1 (sensível ao bloqueio pelas drogas do tipo Losartan). Este receptor faz parte da família dos receptores de sete domínios transmembranais, tipo rodopsina, ligados à proteína G. A ligação da Ang II ao receptor determina uma série de eventos bioquímicos intracelulares que resultam nas variadas funções do peptídio. AAng II, assim como outras substâncias vasoconstritoras, têm como característica principal a mobilização de cálcio intracelular. Neste processo, ocorre a ativação de dois importantes segundos mensageiros o inositol triposfato (IP3) e o diacilglicerol (DG), que resultam do metabolismo de fosfolipídeos da membrana celular, sob ação da fosfolipase C (PLC). A ativação de IP3 está associada à mobilização de cálcio intracelular do retículo endoplasmático, enquanto que o DG participa da ativação da fosfokinase $\mathrm{C}$ (PKC). O PKC, por sua vez, pode fosforilar inúmeras proteínas celulares que estão implicadas não só no mecanismo de contração, mas também em modificação da taxa de transcrição de outros genes. A PKC fosforila proteínas, que se constituem nos terceiros e quartos mensageiros, e agem na região reguladora de diversos genes alterando sua taxa de transcrição. Estes eventos resultam nas alterações fenotípicas relacionados a crescimento (hipertrofia e hiperplasia celular). Desta forma, a Ang II utiliza uma complexa rede de transdução de sinais e eventos bioquímicos intracelulares que resultam nas respostas de contração e proliferação celular.

A despeito do fato de o SRA estar sendo investigado há quase 100 anos, à medida que novas técnicas são incorporadas ao nosso arsenal, novas interações e propriedades do sistema são apreciadas. Neste contexto, existem inúmeras possibilidades para ocor- rências de alterações na regulação do sistema ou nas propriedades de um de seus componentes que podem estar associados ao desenvolvimento e manutenção da hipertensão arterial.

\subsection{Vasopressina}

A vasopressina é um peptídio produzido por neurônios dos núcleos supra-ópticos e paraventricular do hipotálamo e armazenado e liberado pela neuro-hipófise. Os estímulos para sua liberação são aumento na osmolalidade plasmática (por ação direta, em neurônios osmorreceptores), hipovolemia (mediado pela ativação de receptores neurais de volume, localizados nas câmaras atriais cardíacas) e estresses como dor. Níveis séricos normais situam-se entre 2 e $4 \mathrm{pg} / \mathrm{ml}$, podendo atingir $30 \mathrm{pg} / \mathrm{ml}$, durante situações como desidratação severa, por exemplo. As ações da vasopressina no sistema cardiovascular são complexas e mediadas não apenas por efeito vasoconstritor direto (um dos mais potentes vasoconstritores que se conhece), mas também por efeito sobre a função cardíaca e por efeito sobre o sistema nervoso autonômico (aumenta o ganho do reflexo pressorreceptor). A ação vasoconstritora da vasopressina é mediada, através de receptores V1 das células musculares lisas dos vasos. Existem indicações experimentais que a vasopressina, por ação em receptores "V2-like" (células endoteliais ou células musculares lisas?), poderia produzir vasodilatação. Outras evidências indicam que essa vasodilatação pode ser mediada pela liberação do óxido nítrico pela vasopressina. A ligação da vasopressina a receptores vasculares V1 desencadeia aumento de cálcio intracelular, através da ativação de fosfoinositídios. A ação vasoconstritora da vasopressina é variável, dependendo do território. Vasos da musculatura esquelética e pele são os mais sensíveis à ação vasoconstritora da vasopressina, enquanto vasos renais são pouco sensíveis. Apesar de ser um potente vasoconstritor, a contribuição da vasopressina para o tono vascular normal é discutível. Os leitos vasculares mais sensíveis à ação vasoconstritora da vasopressina respondem com algum grau de vasoconstrição, quando os níveis hormonais atingem valores em torno de 10 $\mathrm{pg} / \mathrm{ml}$ que, como discutido anteriormente, encontramse bem acima dos níveis basais. Infusões crônicas de vasopressina, mesmo em doses bastante elevadas, não produzem grandes alterações na pressão arterial. No entanto, outros fatores contribuem para a ausência de elevações sustentadas da pressão arterial durante infusões de AVP. Assim, ao mesmo tempo que age como 
potente vasoconstritor, a vasopressina faz o débito cardiaco diminuir. Isso associado ao escape da retenção de volume de fluido extracelular, durante infusões crônicas do hormônio, explicam a ausência de elevação sustentada da pressão arterial.

Apesar do grande número de evidências, em contrário, há indicações de que esse hormônio possa contribuir no controle tônico da circulação, senão direto, ao menos por mecanismos indiretos. Administração de antagonistas específicos dos receptores V1 da vasopressina, produz queda discreta, mas consistente da pressão arterial.

\subsection{Endotelinas}

As endotelinas são uma família de peptídios vasopressores (ET-1, ET-2,e ET-3) potentes consistindo de 21 aminoácidos e duas pontes dissulfeto produzidos pelas células endoteliais. O peptídio de 21 amino-ácidos é derivado de precursor de 39 aminoácidos que, por sua vez, é produto da preproendotelina de 202 amino-ácidos. Das várias isoformas da endotelina apenas a isoforma $\mathrm{ET}_{1}$ é sintetizada no endotélio. A liberação da $\mathrm{ET}_{1}$ em preparações de anéis de aorta é inibida pelo óxido nítrico. Sua ação biológica é mediada por receptores de membrana que influenciam diferentes mecanismos de mensageiros intracelularmente, dependendo do tipo celular em que está localizado. Foram clonadas duas isoformas de receptores da endotelina $\mathrm{ET}_{\mathrm{A}}$ e $\mathrm{ET}_{\mathrm{B}}$. O receptor $\mathrm{ET}_{\mathrm{A}}$ é distribuído em tecidos como músculo vascular liso, coração, pulmões e intestinos, enquanto o receptor $\mathrm{ET}_{\mathrm{B}}$ é encontrado em células endoteliais, cérebro, pulmões e rins. Nos tecidos vasculares, os receptores $\mathrm{ET}_{\mathrm{A}}$ das células musculares lisas são mediadores de vasoconstrição parácrina, enquanto os receptores $\mathrm{ET}_{\mathrm{B}}$ são mediadores, nas células endoteliais, de funções autócrina da endotelina que resulta em liberação de óxido nítrico. Recentemente, o receptor $\mathrm{ET}_{\mathrm{B}}$ foi encontrado em células musculares lisas e tem demonstrado contribuir para a vasoconstrição mediada, predominantemente, pelos receptores $\mathrm{ET}_{\mathrm{A}}$. $\mathrm{ET}_{\mathrm{A}}$ e $\mathrm{ET}_{\mathrm{B}}$ (são receptores da mesma classe), constituídos de sete domínios "transmembrana" e conectados a proteínas $\mathrm{G}$ intracelulares. As ações primárias em concentrações nanomolares são ativação da fosfolipase $\mathrm{C}$, através de ativação de proteína $\mathrm{G}_{\mathrm{q}}$, induzindo à formação de inositol trifosfato e aumento de cálcio intracelular transitório e conseqüente contração muscular. Esse estágio é seguido por uma contração sustentada, bem como por elevação sustentada do cálcio intracelular. Os receptores $\mathrm{ET}_{\mathrm{A}}$ e $\mathrm{ET}_{\mathrm{B}}$ exercem efeitos opostos na adenilciclase. O receptor $\mathrm{ET}_{\mathrm{A}}$ estimula a adenilciclase, via proteína $\mathrm{G}_{\mathrm{s}}$ e o receptor $\mathrm{ET}_{\mathrm{B}}$ é acoplado negativamente à adenilciclase, presumidamente via proteína $\mathrm{G}_{\mathrm{i}}$. Portanto, o aumento na concentração intracelular de AMPcíclico, produzido pela estimulação de $\mathrm{ET}_{\mathrm{A}}$, pode atenuar contração induzida por ativação da fosfolipase C. A estimulação autócrina de $\mathrm{ET}_{\mathrm{B}}$ nas células endoteliais resulta em liberação de óxido nítrico e pode induzir relaxamento vascular. Assim, a ação vasoconstritora da endotelina pode ser atenuada pela liberação de óxido nítrico pela células endoteliais, induzida pela estimulação de receptores $\mathrm{ET}_{\mathrm{B}}$. Ao nível sistêmico, a ação vasoconstritora das endotelinas pode ser modulada por interferência direta ou indireta das endotelinas na secreção e/ou ação de fatores como renina, fator natriurético atrial, vasopressina e bomba de sódio/potássio.

As endotelinas são secretadas por via constitutiva, indicando que a síntese de endotelinas é, predominantemente, regulada em um passo transcricional, mais que por processos de secreção. A expressão gênica do gen das endotelinas é estimulada por numerosos fatores que incluem, angiotensina II, vasopressina, forbol éster, trombina, epinefrina e insulina. O mecanismo exato, pelo qual alterações no fluxo ou pressão arterial afetam a regulação da produção e secreção de endotelinas pelo endotélio, permanece desconhecido. Apesar de alguns resultados controvertidos, obtidos por alguns autores em diferentes modelos experimentais, em geral, demonstrou-se que o atrito em faixas fisiológicas diminui a produção de endotelinas por células endoteliais.

Apesar de ser tentador especular que um potente agente vasoconstritor como a endotelina possa estar envolvido na patogênese de afecções cardiovasculares, o detalhe dessa participação é pouco conhecido. Níveis plasmáticos elevados de endotelina foram encontrados em grupos de pacientes com hipertensão essencial e hipertensão induzida por ciclosporina. No entanto, a elevação do nível plasmático de endotelina não, necessariamente, leva a aumento sustentado da pressão arterial. Infusão crônica de endotelina em ratos não produz hipertensão sustentada, o mesmo ocorrendo com ratos transgênicos, produzidos pela adição de cópia do gen ET-2 humano da endotelina. Isso indica que a elevação dos níveis plasmáticos de endotelinas na hipertensão arterial essencial e na hipertensão induzida por ciclosporina exercem apenas papel coadjuvante na patogênese ou se elevam, secundariamente, durante o estabelecimento do processo hipertensivo. 


\section{FATORES DEPRESSORES}

\section{1 Óxido nítrico}

O óxido nítrico é uma substância simples (também um radical livre), ativador endógeno da forma solúvel da guanilato ciclase, produzido na reação de conversão do aminoácido L-Arginina em Citrulina, catalizada pela enzima óxido nítrico sintetase na presença de $\mathrm{O}_{2}$ e NADPH. Há pouca informação experimental sobre o mecanismo, pelo qual o aumento de fluxo leva à ativação da via metabólica de síntese de óxido nítrico. Sabe-se, por exemplo, que aumentos agudos e crônicos de fluxo aumentam a expressão gênica do óxido nítrico sintetase em células endoteliais, obtidas da aorta. Deve-se salientar que o óxido nítrico, além de exercer efeito vasodilatador direto, através do aumento da concentração intracelular de GMP cíclico, exerce outras funções, direta ou indiretamente, ligadas ao controle cardiovascular. Assim, há evidências de que o óxido nítrico 1) seja um neurotransmissor em diversos níveis do sistema nervoso, especialmente em vias responsáveis pela atividade simpática; 2) atue como antiagregante plaquetário, e 3) seja mediador da secreção de renina pelas células justaglomerulares.

A contribuição relativa dessa substância para o controle do tono vascular permanece desconhecida. É possível que sua importância seja heterogênea nos diferentes leitos vasculares. Parte da dificuldade em se conhecer a contribuição do óxido nítrico, para o tono basal, deve-se à dificuldade de detecção da substância circulante, principalmente, porque sua vida média na circulação é pequena ( 1 segundo). As dosagens de nitratos e nitritos, derivados que são produzidos na metabolização do óxido nítrico, no plasma e na urina, sofrem de inespecificidade, pois outras fontes do metabolismo intermediário contribuem para seus níveis circulantes. As principais evidências, indicando contribuição significativa desse sistema, para o controle basal da resistência periférica provêm de estudos utilizando inibidores da atividade da enzima óxido nítrico sintetase (L-NAME, por exemplo). A veracidade dessa comprovação experimental, também, apresenta diversas críticas, dentre elas 1) o bloqueio produzido pelo L-NAME não é específico para a NOS, podendo bloquear várias enzimas, que contêm grupamento "heme" em sua estrutura. Algumas enzimas com essas características catalizam a síntese de produtos vasoativos, como a P-450 envolvida no metabolismo do ácido aracdônico na produção de eicosanóides; 2) A administraçao de L-NAME produz ativação de sis- temas pressores como o simpático e o sistema reninaangiotensina, provavelmente dependente da inibição da síntese de óxido nítrico no sistema nervoso autonômico; 3) a administração de L-NAME produz agregação plaquetária que no rim pode produzir glomerulopatia e ativar o sistema renina-angiotensina por isquemia renal.

Há interesse substancial no possível papel do óxido nítrico na patogênese da hipertensão. As investigações têm sido focalizadas na deficiência do óxido nítrico como causa de hipertensão e na possibilidade de estimular a produção vascular de óxido nítrico como um método de correção da hipertensão. Em diversos modelos de hipertensão arterial, bem como em indivíduos hipertensos, a vasodilatação produzida por acetilcolina (endotélio dependente) foi demonstrada estar atenuada. Há dúvidas se estas alterações são primárias ou secundárias às alterações da pressão arterial. De qualquer forma, a atenuação da ação vasodilatadora do endotélio deve potenciar a ação vasoconstritora de agentes pressores, contribuindo para o aumento de resistência periférica na hipertensão arterial. Recentemente, experimentos em camundongos, obtidos com técnica de "knock out" de manipulação gênica, revelou que animais deficientes da isoenzima óxido nítrico sintase endotelial apresentam elevações discretas, mas sustentadas da pressão arterial, sugerindo que alterações desse sistema podem estar envolvidas na patogênese da hipertensão arterial.

\subsection{Prostaciclina (Prostaglandina $\mathrm{I}_{2}$ )}

A PGI2 é um dos produtos da metabolização do ácido aracdônico pela ciclooxigenase. Seus níveis circulantes e locais são determinados, basicamente, pela liberação do ácido arcdônico pela ação de uma fosfolipase nos triglicerídios da membrana celular. Sua meia vida é maior que a do óxido nítrico $(\sim 3$ minutos em $\mathrm{pH}$ fisiológico in vitro), mas sua potência como vasodilatador é menor. Além de vasodilatador, a prostaciclina é um potente agente antiagregante plaquetário. Como no caso do óxido nítrico, seu efeito vasodilatador e antiagregante plaquetário são mediados pelo aumento da disponibilidade de GMP cíclico intracelular, por ativação da guanilato ciclase solúvel (citoplasmática). Sua síntese e liberação pelas células endoteliais ocorrem não somente em resposta a agonistas (ativadores da fosfolipase), mas também na presença de aumento de fluxo. Como no caso do óxido nítrico, o mecanismo pelo qual o aumento de fluxo faz aumentar sua secreção é desconhecido. Sua importância como modulador do tonus vascular é, também, desconhecida. 


\subsection{Peptidio natriurético atrial}

O peptídio natriurético atrial (ANP) é secretado, primariamente, por miócitos atriais em resposta ao estiramento local dos átrios. As ações combinadas do ANP nos vasos, rins e adrenais reduzem, tanto aguda como cronicamente, a pressão arterial, assim como o volume intravascular. A redução da pressão arterial é conseqüência da redução da resistência vascular (em parte mediada por relaxamento direto do músculo vascular liso), diminuição do débito cardíaco e diminuição do volume intravascular. Nos rins, o ANP age em receptores específicos dos microvasos renais e epitélio tubular, induzindo hiperfiltração, inibição do transporte de sódio e supressão da secreção de renina, todos responsáveis por produzir diurese e natriurese. O ANP, também, diminui a pressão arterial e o volume intravascular por inibir a síntese de aldosterona tanto, indiretamente, por inibir a secreção de renina como, diretamente, por ação nas células da camada glomerulosa da adrenal. Finalmente, o ANP facilita a transudação de líquido para o interstício, o que contribui para a redução do volume intravascular.

Experimentos in vitro e in vivo sobre o efeito vasodilatador do ANP são conflitantes. Apesar de produzir relaxamento vascular em preparações de vasos de condutância em preparações in vitro, não existem estudos conclusivos demonstrando que o ANP induz vasodilatação em vasos que regulam a resistência periférica. Em ratos não anestesiados, dependendo do tono basal e da atividade de sistemas pressores, infusões de ANP aumentam o fluxo sanguíneo nos pulmões, coração, baço, leito mesentérico e rins, sem alterações significativas no fluxo cerebral, pele e músculos esqueléticos. No entanto, a resistência periférica total aumenta, durante infusões de ANP, seu efeito hipotensor devendo-se mais à queda no débito cardíaco. Em ratos com bloqueio farmacológico do simpático, infusões de ANP levam à diminuição da resistência vascular, indicando que as ações do ANP dependem do nível basal da atividade autonômica dos animais.

Como outros peptídios, o ANP liga-se a sítios estereoespecíficos da superfície celular para evocar respostas fisiológicas nas células alvo. Essa interação hormônio-receptor, por sua vez, ativa a guanilato ciclase associada à membrana celular, convertendo o MgGMP em GMP cíclico. O GMP cíclico por sua vez, estimula "proteínas kinases" dependentes de GMP cíclico, que são as responsáveis pela fosforilação de um grande número de proteínas intracelulares, evento bioquímico que é essencial para a expressão das ações fisiológi- cas do ANP. Além disso, o ANP também inibe a atividade da adenilato ciclase em alguns tecidos, o que indica a possibilidade que alguns efeitos fisiológicos do ANP sejam devidos à interação com agonistas estimuladores de AMP cíclico.

\section{O COMPONENTE GENÉTICO E O COMPONEN- TE AMBIENTAL}

Nosso código genético está armazenado em 23 pares de cromossomos que contém cerca de $100 \mathrm{mil}$ genes, responsáveis pela produção de cerca de 100 mil proteínas utilizadas não só para a constituição do organismo como, muito especialmente, nos comandos que irão regular as diferentes funções, inclusive os múltiplos componentes de regulação da pressão arterial. Uma alteração genética transmitida aos descendentes poderá ser responsável pela hipertensão? Essa pergunta fundamental foi respondida de forma brilhante pelos pesquisadores japoneses Okamoto e Aoki que, na década de 60 , desenvolveram por acasalamento uma linhagem de ratos (SHR de spontaneous hipertensive rats ou "rato com hipertensão espontânea") que, sistematicamente, tornam-se hipertensos aos três ou quatro meses de vida. Os ratos não nascem hipertensos, mas assim como ocorre no homem, desenvolvem hipertensão quando atingem certo grau de maturidade. Interessante, também, é que a patologia da hipertensão nesses animais é muito semelhante à hipertensão humana, isto é, a sobrecarga de pressão, com o tempo, compromete o coração, os rins e o cérebro.

Como identificar os genes responsáveis pela hipertensão no rato SHR? Estudos recentes, utilizando de modernas metodologias de biologia molecular, procuram identificar nos netos de ratos nascidos de um avô normotenso e de outro hipertenso puros, quais os genes associados à hipertensão que são transmitidos. A tarefa é difícil porque deve-se dispor de marcadores, distribuídos em todos os cromossomos para identificar os fragmentos originados do ancestral hipertenso ou normotenso e que contêm os genes responsáveis pela hipertensão. Cinco segmentos, distribuídos nos 21 pares de cromossomos do rato, mostraram-se significantes na determinação da hipertensão associada à sobrecarga de sal. Isso significa que, em cada uma das regiões, deve existir pelo menos um gen ligado ao complexo sistema de regulação da pressão arterial contribuindo para a hipertensão. Essa abordagem vem permitindo elucidar a base molecular dos defeitos que promovem a hipertensão no rato, e tem 
fornecido informações vitais para identificarmos se esses mesmos fatores são importantes na hipertensão humana.

A utilização do rato, como modelo de hipertensão genética, é muito importante, uma vez que o seu ciclo de vida e o tempo para reprodução são muitíssimos menores que os do homem. Além disso, no rato, podemos obter linhagens geneticamente idênticas, fixando-se assim o componente genético dos estudos. A partir daí, pode-se controlar no laboratório as variáveis ambientais (como o sal e o estresse) e fazer estudos sistematizados, impossíveis de serem realizados no homem. Essa espécie, assim como o camundongo, também vem sendo usado para o desenvolvimento de animais transgênicos, onde um gen específico tem sua produção aumentada, através da incorporação de uma ou mais cópias no genoma animal. Várias técnicas podem ser utilizadas, mas a mais freqüente é injetarse o segmento de DNA contendo o gen de interesse em um óvulo fertilizado que, posteriormente, é reintroduzido em uma rata pseudográvida que levará a gestação a termo. A incorporação do DNA ao genoma é um processo aleatório e não se tem controle sobre o número de cópias ou do local onde este material foi introduzido no genoma (pode ocorrer em qualquer dos 21 pares de cromossomos do rato ou camundongo). Existem, no entanto, técnicas para identificar os animais em que a incorporação ocorre.

No caso de hipertensão arterial, o uso de animais transgênicos tem sido muito útil para demonstrar, no animal inteiro, as repercussões do aumento da expressão de um determinado gen sobre os diversos sistemas que controlam a pressão arterial. Notadamente, o exemplo mais bem conhecido é o do rato transgênico, contendo cópias extras do gen da renina de camundongo desenvolvido por Mullins e Ganten. Estes animais apresentam um quadro hipertensivo que responde ao tratamento com inibidores da enzima de conversão. Surpreendentemente, os níveis plasmáticos e renais de renina são baixos, enquanto que a renina na adrenal está aumentada. Estes resultados indicam dois aspectos muito importantes. Primeiro, a disfunção de um único gen, o gen da renina, resulta no desenvolvimento de um quadro hipertensivo importante. Segundo, a disfunção do sistema renina/angiotensina limitou-se à adrenal e, talvez, a alguns centros de sistema nervoso, sugerindo um papel importante dos sitema renina/angiotensina teciduais para o desenvolvimento da hipertensão.

Um outro modelo de animal, geneticamente, manipulado que vem sendo utilizado é o dos camun- dongos "Knock out" onde um determinado gen é suprimido, através de troca do gen normal por um modificado e sem função. Isto é obtido pelo processo de recombinação homóloga. Este procedimento ocorre com freqüência ainda menor do que a incorporação do transgene, mas sua principal diferença é que a retirada e a incorporação do fragmento de DNA, contendo o gen modificado, ocorrem no local de origem daquele gen. Este procedimento, também, pode ser feito por microinjeção, mas, ao invés de se utilizar um óvulo fertilizado, usa-se uma célula multipotente (stem cell). Os animais são selecionados e cruzados para obtenção de homozigotos onde as duas cópias do gen são "nocauteadas". Utilizam-se estes animais para estudar a função de um gen, através da sua supressão. É importante considerar, entretanto, que se este gen for fundamental para a fase de desenvolvimento dos animais eles não sobreviverão, e o experimento não poderá ser realizado. Recentemente, foi observado que a eliminação do gen da endotelina não era compatível com o desenvolvimento dos animais, pois segmentos cranio faciais parecem ser dependentes da integridade deste gen para o completo desenvolvimento. Um outro aspecto importante é que existe redundância entre os sistemas que controlam as diferentes funções no organismo e portanto, o efeito da remoção isolada de um gen pode ser mascarado por mecanismos compensatórios que procuram manter a função.

Os camundongos "knock out" têm produzido resultados interessantes para a compreensão dos diversos sistemas de controle de pressão arterial. Por exemplo, a eliminação de uma das cópias do gen do peptídio atrial natriurétrico faz com que os animais respondam com aumento de pressão arterial à sobrecarga salina, demonstrando de forma inequívoca a importância do sistema para a homeostasia do metabolismo de sal e água. Os animais com eliminação do gen da ECA e da NO sintetase endotelial têm diminuição significativa dos níveis pressórios basais. Recentemente, Oliver Smithies e colaboradores modificaram esta técnica para permitir não só a eliminação de um gen mas, também, a incorporação de uma cópia normal de um determinado gene no seu local original, resultando na sua duplicação. É importante enfatizar que, neste procedimento, há incorporação do gen completo, incluindo tanto a região codificadora quanto a regulatória, resultando na sua duplicação. Desta forma, pode-se obter animais com $0,1,2,3$ e 4 cópias do mesmo gen na sua localização correta, permitindo estudos de "dosagem gênica". A motivação para este estudo se originou da observação do grupo de Corvol 
e colaboradores, de que variações no gen do angiotensinogênio, associadas ao aumento dos níveis séricos do angiotesinogênio, cossegregam com a hipertensão em duas populações de hipertensos, uma na França e outra nos EUA. Smithies e colaboradores testaram esta hipóteses no laboratório com animais contendo número diferente do gen do angiotensinogênio. Elegantemente, eles demonstraram que os níveis de angiotensiangênio aumentavam com o número de cópias do gene e isto resultou em um aumento progressivo dos níveis de pressão arterial. Estes resultados ilustram a potencialidade das técnicas de Biologia e Genética moleculares para a compreensão das bases moleculares da hipertensão arterial. É fundamental salientar que a utilização destas técnicas está permitindo que, conhecimentos iniciados no laboratório possam ser testados em populações de pacientes e viceversa, de tal forma que as limitações e dificuldades de uma ou outra abordagem sejam mininizadas.

Em síntese, a hipertensão arterial é uma doença multifatorial, em que o substrato genético alterado predispõe o indivíduo à ação de fatores ambientais, como sal e álcool em excesso, estresse, etc que desencadeiam o desequilíbrio dos complexos sistemas (hipertensores e hipotensores) que regulam a pressão arterial, provocando a hipertensão.

KRIEGER EM; FRANCHINI KG \& KRIEGER JE. Pathophysiologyof primary hypertension. Medicina, Ribeirão Preto, 29: 181-192, apr./sept. 1996.

ABSTRACT: The increased peripheral resistance is considered the major cause of primary hypertension. The functional and structural factors responsible for the resistance vascular changes in hypertension are reviewed. The most important functional mechanisms acting on the resistance vessels are represented by pressor (neurogenic, angiotensin, vasopressin, endotelin, etc) and depressor. (NO, prostacyclin, atrial natriuretic peptide etc) factors. The increased activity of the vascular effector cells depends on complex influences ascribed to an imbalance of production between the pressor and depressor factors. The structural mechanism is represented by an increase in the media/lumen ration of the resistance vessels. The reduction in lumen can be produced by growth of the wall into the lumen (hypertrophy) or by a rearrangement of the amount of material around the smaller lumen (remodeling). Finally, the importance of genetic predisposition in hypertension and of genetic defects, presently analysed by powefull molecular biology methods were reviewed.

UNITERMS: Hypertension. Vascular Resistence. Vasoconstriction. Vasodilatation. Hypertrophy. Genetics.

\section{BIBLIOGRAFIA RECOMENDADA:}

1 - DAVIES PF. Flow-mediated endothelial mechanotransduction. Physiol Rev 75: 519-560, 1995

2 - FRANCHINI KG \& KRIEGER EM. Neurogenic hypertension in the rat. In: GANTEN D \& JONG W de, eds. Experimental and genetic models of hypertension, Elsevier Science BV, Amsterdam, p. 482-500, 1994. (Handbook of Hypertension, 16).

3 - FURCHGOT RF \& ZAWADSKI JV. The obligatory role of the endothelial cells in the relaxation of arterial smooth muscle cells by acetylcholine. Nature 288: 373-376, 1981.

4 - INAGAMI T; NARUSE M \& HOOVER R. Endothelium as an endocrine organ. Annu Rev Physiol 57: 171-189, 1995.

5 - JULIUS S. Sympathetic hyperactivity and coronary risk in hypertension. Hypertension 21: 886-893,1992.

6 - KAMIYA A \& TOGAWA A. Adaptive regulation of wall shear stress to flow change in the canine carotid artery. Am J Physiol 239 (Heart Circ Physiol 8): H14-H21, 1980.
7 - KIM H-S et al. Genetic control of blood pressure and the angiotensinogen locus. Proc Natl Acad Sci USA 92:27352739, 1995.

8 - KRIEGER EM. Arterial baroreceptor resetting in hypertension (The JW McCubbin Memorial Lecture). Clin Exp Pharmacol Physiol Suppl 15:3-17, 1989.

9 - KRIEGER JE \& DZAU VJ. Molecular biology of hypertension. Hypertension 18 (suppl I): I-3-I-17; 1991.

10 - MILLER VM \& VANHOUTTE PM. Enhanced release of endothelium-derived relaxing factor by chronic increase in blood flow. Am J Physiol 255 (Heart Circ Physiol 24): H446H451, 1988.

Recebido para publicação em 16/01/96

Aprovado para publicação em 25/04/96 